\title{
Work-related ill health in general practice, as reported to a UK-wide surveillance scheme
}

\author{
Louise Hussey, Susan Turner, Kevan Thorley, Roseanne McNamee and Raymond Agius
}

\author{
ABSTRACT \\ GPs with training in occupational medicine report \\ cases of work-related ill health and sickness absence \\ to The Health and Occupation Reporting network in \\ General Practice (THOR-GP) using an online webform. \\ This report describes the data reported in 2006 and \\ 2007. GPs mainly reported musculoskeletal disorders \\ and mental ill-health. A much larger proportion of the \\ mental ill-health cases were sickness-absence \\ certified, making up $55.9 \%$ of the total days certified. \\ Musculoskeletal disorders are the most frequently \\ reported diagnoses of work-related ill health, but \\ mental ill-health is responsible for most work-related \\ sickness absence.

\section{Keywords} \\ general practice; industry; mental ill-heath; \\ musculoskeletal; occupational health; sickness \\ absence.
}

\section{INTRODUCTION}

In 2006-2007, an estimated 2.2 million people selfreported work-related ill health. Of these cases, approximately three-quarters were musculoskeletal or psychiatric/psychological diagnoses. ${ }^{1}$ The sickness absence resulting from these work-related diagnoses (36 million days lost $\left.{ }^{1}\right)$ makes up around one-quarter of the total days lost in the UK. ${ }^{2}$ Preventative measures aiming to reduce the burden of work-related ill health and associated sickness absence require information on causal factors and employment sectors at risk. One source of such information is The Health and Occupation Reporting network (THOR), ${ }^{3}$ comprising surveillance schemes that collect anonymised case reports of work-related ill health as seen by clinical specialists and occupational physicians. ${ }^{4-7}$

There is little published research on work-related ill health seen by GPs, ${ }^{8}$ although some estimates suggest that over one-third of patients in general practice settings attribute their problems to work..$^{9,10}$ Non-recognition and under-reporting of workrelated ill health have also been recognised as important factors within community-based studies, ${ }^{11}$ with a lack of vocational occupational medicine training being a possible contributing factor. ${ }^{12,13}$

THOR-GP (The Health and Occupation Reporting network in General Practice) was established to assess the extent and nature of work-related ill health seen in general practice. This paper describes THOR-GP's methodology and data collected from the first two full calendar years (2006-2007) of the scheme.

\section{METHOD}

From May 2005 onwards, qualified GPs with additional training in occupational medicine to at least diploma level (DOccMed of the Faculty of Occupational Medicine of The Royal College of Physicians of London ${ }^{14}$ ) were invited to join THORGP. GPs were identified using examination pass lists, physicians' websites citing areas of specialist interest, ${ }^{15}$ and past student intakes from the Diploma course at the Centre for Occupational and 


\section{How this fits in}

There is little published research on work-related ill health seen by GPs.

However, some UK-based and international studies suggest work-related ill

health conditions are frequent in general medical practice clinics. This study

describes the extent and nature of work-related ill health and resulting sickness

absence seen in general practice. More than half of the incident ill health is

musculoskeletal and this contrasts with certified days lost, as more than half of

these are related to mental ill-health.

Environmental Health at the University of Manchester. ${ }^{16}$ Recruitment was a continual process, with GPs commencing reporting the month after agreeing to participate. Therefore, reporting started in June 2005, while participant numbers increased until the recruitment target of 300 GPs was reached in April 2006.

THOR-GP reporting, coding, and analytical methods were developed from those within an established THOR scheme, known as OPRA (Occupational Physicians Reporting Activity). ${ }^{7}$ This incorporates newly developed electronic reporting systems using a webform located on the THOR-GP website. ${ }^{17}$ GPs complete details of any cases they see in their general practice, which they believe to have been caused or aggravated by work.

Webform details include: demographic information (age, sex, and first half of postcode), diagnosis, occupation, industry, and suspected causal agent/task/event. With each reported case GPs provide any additional information on sickness certification issued and patient referrals. GPs are also asked to return a blank report if they have 'nothing to report' in any month. Reminders are sent out twice monthly by email to encourage any outstanding cases or 'nothing to report' returns.

THOR-GP data from 2006 and 2007 were analysed using SPSS (version 15.0).

\section{RESULTS}

A total of 267 GPs reported to THOR-GP, returning 2872 cases of work-related ill health (2923 diagnoses, some cases being comorbid), which resulted in 0.4 cases/reporter/month. Mean age of individuals whose cases were reported by GPs was 40.4 years.

Over half the cases reported by GPs were of musculoskeletal disorders, while mental ill-health accounted for almost one-third of the diagnoses. Of all the 2872 cases reported, $50.0 \%$ of patients were issued with sickness certification. The proportion issued with certification differed greatly by diagnostic category, with a much larger proportion of those with mental ill-health issued with certification than those with other diagnoses (Table 1). There were 40317 days certified from the reported cases. Reports of mental ill-health were responsible for the majority of these (55.9\%).

Within the musculoskeletal category, most reports were of either hand/wrist/arm or lumbar spine/trunk disorders. For mental ill-health diagnoses, GPs mainly reported 'stress', and anxiety/depression. Almost $80 \%$ of the skin cases were reports of contact dermatitis. Respiratory disease cases consisted of asthma, asthma-related symptoms, or rhinitis. Audiological diagnoses were most often noise-induced hearing loss, while the 'other' category included minor trauma and infections not classified elsewhere (for example, ocular diagnoses).

Fewer cases were reported in females $(43.7 \%)$, and this pattern for fewer female reports was noted in all diagnostic categories apart from mental ill-health where females accounted for $58.5 \%$ of cases.

Cases were reported most frequently from the healthcare sector (13.5\%), construction (10.6\%), public administration and defence $(9.5 \%)$, and retail (9.5\%). The diagnostic case-mix differed greatly between industries: sectors such as construction

Table 1. Diagnostic groups reported by GPs 2006 to 2007.

\begin{tabular}{lccccc} 
Diagnoses & $\begin{array}{c}\text { Number of } \\
\text { diagnoses }\end{array}$ & $\begin{array}{c}\text { Percentage of } \\
\text { total diagnoses }\end{array}$ & $\begin{array}{c}\text { Percentage of } \\
\text { diagnoses issued with } \\
\text { sickness certification }\end{array}$ & $\begin{array}{c}\text { Number of days } \\
\text { certified } \\
\text { (diagnoses) }\end{array}$ & $\begin{array}{c}\text { Percentage of } \\
\text { total days certified } \\
\text { (diagnoses) }\end{array}$ \\
\hline Musculoskeletal & 1558 & 53.3 & 42.2 & 14865 & 36.0 \\
\hline Mental ill-health & 869 & 29.7 & 78.8 & 23099 & 55.9 \\
\hline Skin & 268 & 9.2 & 14.6 & 646 & 1.6 \\
\hline Respiratory & 87 & 3.0 & 33.3 & 692 & 1.7 \\
\hline Audiological & 17 & 0.6 & 23.5 & 238 & 0.6 \\
\hline Other diagnoses & 124 & 4.2 & 46.8 & 1748 & 4.2 \\
\hline Total (diagnoses) & $2923^{\text {a }}$ & 100.0 & N/A & $41288^{\text {a }}$ & 100.0 \\
\hline
\end{tabular}

asome cases are comorbid; therefore, there are more diagnoses than cases and more days certified when diagnoses are analysed separately. 
Table 2. Diagnoses reported by GPs by industry 2006 to 2007 .

\begin{tabular}{|c|c|c|c|c|c|c|c|c|}
\hline \multirow[b]{2}{*}{ Industry } & \multicolumn{2}{|c|}{ Musculoskeletal } & \multicolumn{2}{|c|}{ Mental ill-health } & \multicolumn{2}{|c|}{ Other cases } & \multicolumn{2}{|c|}{ Total } \\
\hline & $\begin{array}{l}\text { Number of } \\
\text { diagnoses }\end{array}$ & $\begin{array}{c}\text { Percentage } \\
\text { within industry }\end{array}$ & $\begin{array}{l}\text { Number of } \\
\text { diagnoses }\end{array}$ & $\begin{array}{c}\text { Percentage } \\
\text { within industry }\end{array}$ & $\begin{array}{l}\text { Number of } \\
\text { diagnoses }\end{array}$ & $\begin{array}{c}\text { Percentage } \\
\text { within industry }\end{array}$ & $\begin{array}{c}\text { Total } \\
\text { diagnoses }^{\mathrm{a}}\end{array}$ & $\begin{array}{c}\text { Total } \\
\text { percentage }\end{array}$ \\
\hline All cases & 1558 & 53.3 & 869 & 29.7 & 496 & 17.0 & 2923 & 100.0 \\
\hline Health and social care & 169 & 42.9 & 187 & 47.5 & 38 & 9.6 & 394 & 100.0 \\
\hline Construction & 240 & 77.4 & 23 & 7.4 & 47 & 15.2 & 310 & 100.0 \\
\hline Public administration and defence & 113 & 40.5 & 120 & 43.0 & 47 & 16.8 & 280 & 100.0 \\
\hline Retail & 169 & 61.0 & 84 & 30.3 & 24 & 8.7 & 277 & 100.0 \\
\hline Education & 39 & 24.1 & 104 & 64.2 & 19 & 11.7 & 162 & 100.0 \\
\hline Hotel and catering & 63 & 46.0 & 25 & 18.2 & 49 & 35.8 & 137 & 100.0 \\
\hline Other industries & 765 & 56.1 & 326 & 23.9 & 272 & 19.9 & 1363 & 100.0 \\
\hline
\end{tabular}

a Some cases are comorbid; therefore, there are more diagnoses than cases.

and retail had higher levels of musculoskeletal disorders, whereas industries such as health and social care, public administration and defence, and education had more reports of mental ill-health (Table 2). Notably, hotel and catering had larger proportions of work-related skin conditions.

\section{DISCUSSION}

\section{Summary of main findings}

These data highlight the burden of work-related mental ill-health and musculoskeletal disorders, when compared to other morbidities, and in particular the extent to which work-related mental ill-health contributes to sickness absence. Musculoskeletal disorders are the most frequently reported diagnoses, but mental ill-health is responsible for most work-related sickness absence, with over three-quarters of these cases issued with sickness certification making up over half of the total days certified.

\section{Strengths and limitations of the study}

THOR-GP data will be used to calculate national incidence rates. To do this it is necessary to characterise the THOR-GP denominator and assess how the THOR-GP population compares to the entire UK. Preliminary analyses have been carried out to show how the areas represented by THOR-GP practices compare to the whole of the UK. Office of National Statistics' data showed that areas represented by THOR-GP practices were almost identical to the whole of the UK in their industrial breakdown (Appendix 1). Office for ational Statistics data showed that areas represented by THOR-GP practices were proportionally almost identical to the whole of the UK in their industrial breakdown. ${ }^{18}$

THOR-GP benefits from the contribution of reporters who are all medically-qualified practitioners with additional training in occupational medicine to consider work and its attribution in relation to ill health. This may mean that they differ from other GPs, not only in their distribution, but also in their clinical behaviour and reporting preferences and patterns. Thus, one study has shown that GPs working part-time in occupational medicine issued certificates of significantly shorter duration. ${ }^{19}$ THORGPs may also differ from other GPs in their working timetables and tasks within their practices. These are all issues currently under investigation.

\section{Comparison with existing literature}

Mild mental health disorders have also been shown to be responsible for the most days certified from all GP consultations (39.7\%; although not solely workrelated), ${ }^{20}$ followed by musculoskeletal disorders (15.4\%). All other diagnoses made up the remaining $44.9 \%$ of days certified, compared to just $8.2 \%$ of the work-related cases reported to THOR-GP. One study found that doctors were more likely to issue a sick note to a patient with a psychological problem because he/she needed one, whereas they would issue certification to a patient with physical problem to maintain a relationship with them. ${ }^{21}$ Little information has been published on the proportion of clinical practice that is work related, but estimates range from $39.0 \%$ based on patients' opinions, ${ }^{9}$ to $7.2 \%^{22}$ and $16.0 \%^{10}$ based on GPs' case evaluations.

Other $\mathrm{THOR}^{3}$ schemes are extremely valuable in evaluating trends, ${ }^{23}$ and assessing hazards in the workplace, but data will only be captured by these schemes if the patient is referred to a clinical specialist or if they have access to an occupational physician. Only a small proportion of the UK workforce has access to occupational health services (12-34\%), with OPRA reporting likely to originate from larger industries. ${ }^{14,24}$ The majority of 
the population has access to a $\mathrm{GP}^{25}$ and GPs are usually the first port of call for patients with any sort of ill health. GPs are also in the unique position of being able to provide additional information on sickness absence. Therefore, THOR-GP may give a truer picture of the national burden of work-related ill health than that reported by other groups of physicians in the UK.

\section{Implications for clinical practice and future research}

THOR-GP highlights the potential for data collected from general practice on work-related ill health and sickness absence. Such information will make an important contribution to building up a picture of the interaction between work and health and the identification of workplace hazards and populations at risk. Therefore, this is valuable in planning health interventions to reduce risk to employees and absence from work. The variation in case-mix between industries illustrates that measures put in place to prevent work-related ill health need to be made to fit the specific industries rather than being a blanket policy approach. ${ }^{2}$

\section{Appendix}

Additional information can be found in the online version of this article

\section{Funding body}

THOR is partly funded by grants from the Health \& Safety Executive (4307/R56.069 and 4496/R60.002) awarded to Professor Raymond Agius and co-investigators. This paper expresses the views of the authors, and not necessarily of the funders

\section{Ethical approval}

Multicentre Research Ethics Committee approval has been given for THOR (MREC 02/8/72)

\section{Competing interests}

The authors have stated that there are none

\section{Acknowledgements}

We would like to thank all GPs who participate in THORGP. Thanks are also due to Susan Taylor and Ruth Parker for their research and administrative assistance. Physicians who wish to join THOR-GP/THOR and participate in reporting can find further details at http://www.medicine.manchester.ac.uk/coeh/thorgp/

\section{Discuss this article}

Contribute and read comments about this article on the Discussion Forum: http://www.rcgp.org.uk/bjgp-discuss

\section{REFERENCES}

1. Health and Safety Executive. HSE statistics - key figures for 2006/07. http://www.hse.gov.uk/statistics/index.htm (accessed 21 Jul 2008).

2. Black C. Working for a healthier tomorrow - Dame Carol Black's review of the health of the working age population. London: TSO, 2008.

3. University of Manchester. The Health and Occupation Reporting
Network (THOR).

http://www.medicine.manchester.ac.uk/coeh/thor/ (accessed $21 \mathrm{Jul}$ 2008).

4. Meredith SK, Taylor VM, McDonald JC. Occupational respiratory disease in the United Kingdom 1989: a report to the British Thoracic Society and the Society of Occupational Medicine by the SWORD project group. Br J Ind Med 1991; 48(5): 292-298.

5. Meyer JD, Chen Y, Holt DL, et al. Occupational contact dermatitis in the UK: a surveillance report from EPIDERM and OPRA. Occup Med (Lond) 2000; 50(4): 265-273.

6. Cherry NM, Meyer JD, Chen Y, et al. The reported incidence of work-related musculoskeletal disease in the UK: MOSS 1997-2000. Occup Med (Lond) 2001; 51(7): 450-455.

7. Cherry NM, Meyer JD, Holt DL, et al. Surveillance of work-related diseases by occupational physicians in the UK: OPRA 1996-1999. Occup Med (Lond) 2000; 50(7): 496-503.

8. Weevers HJ, van der Beek AJ, Anema JR, et al. Work-related disease in general practice: a systematic review. Fam Pract 2005; 22(2): 197-204.

9. Harber P, Mullin M, Merz B, Tarazi M. Frequency of occupational health concerns in general clinics. J Occup Environ Med 2001; 43(11): 939-945.

10. Benavides FG, Castejon J, Gimeno D, et al. Certification of occupational diseases as common diseases in a primary health care setting. Am J Ind Med 2005; 47(2): 176-180.

11. De Bono J, Hudsmith L. Occupational asthma: a community based study. Occup Med (Lond) 1999; 49(4): 217-219.

12. Parker G. General practitioners and occupational health services. $\mathrm{Br}$ J Gen Pract 1996; 46(406): 303-305.

13. Morgan DR. The general practitioners' view. Occup Med (Lond) 1999; 49(6): 403-405.

14. Faculty of Occupational Medicine of the Royal College of Physicians. Provision of occupational health services to small and medium sized enterprises (SMEs). London: Faculty of Occupational Medicine of the Royal College of Physicians, 2007.

http://www.facoccmed.ac.uk/library/docs/pp_smes.pdf (accessed 21 Jul 2008).

15. Healthcare Knowledge Limited. Specialist Info.com. http://www.specialistinfo.com/index.php (accessed 21 Jul 2008).

16. Donnelly AB, Agius RM. The distance learning courses in occupational medicine - 20 years and onwards. Occup Med (Lond) 2005; 55(4): 319-323.

17. University of Manchester. The Health and Occupation Reporting Network in General Practice (THOR-GP). http://www.medicine.manchester.ac.uk/coeh/thorgp/ (accessed 21 Jul 2008).

18. Office for National Statistics. Local authority datasets. http://www.statistics.gov.uk/about/methodology_by_theme/area_cl assification/datasets.asp (accessed 1 Aug 2008).

19. Tellnes G, Sandvik L, Moum T. Inter-doctor variation in sickness certification. Scand J Prim Health Care 1990; 8(1): 45-52.18. Shiels C, Gabbay MB, Ford FM. Patient factors associated with duration of certified sickness absence and transition to long-term incapacity. Br J Gen Pract 2004; 54(499): 86-91.

20. Campbell A, Ogden J. Why do doctors issue sick notes? An experimental questionnaire study in primary care. Fam Pract 2006; 23(1): 125-130.

21. Copeman D, Skinner J, Burgin A. Occupational injury and disease among patients presenting to general practitioners in a community health centre. Aust J Public Health 1992; 16(4): 413-418.

22. McNamee R, Carder M, Chen Y, Agius R. Measurement of trends in incidence of work-related skin and respiratory disease, UK 1996-2005. Occup Environ Med 2008; DOI: 10.1136/oem.2007.036731

23. McDonald JC. The estimated workforce served by occupational physicians in the UK. Occup Med (Lond) 2002; 52(7): 401-406.

24. Office of Health Economics. Compendium of health statistics. 8th edn. London: Office of Health Economics, 1992. 


\section{Appendix 1. Industrial employment of the population of combined output areas \\ (England, Scotland, and Wales) compared to those represented by THOR-GP practices.}

\section{England, Scotland and Wales}
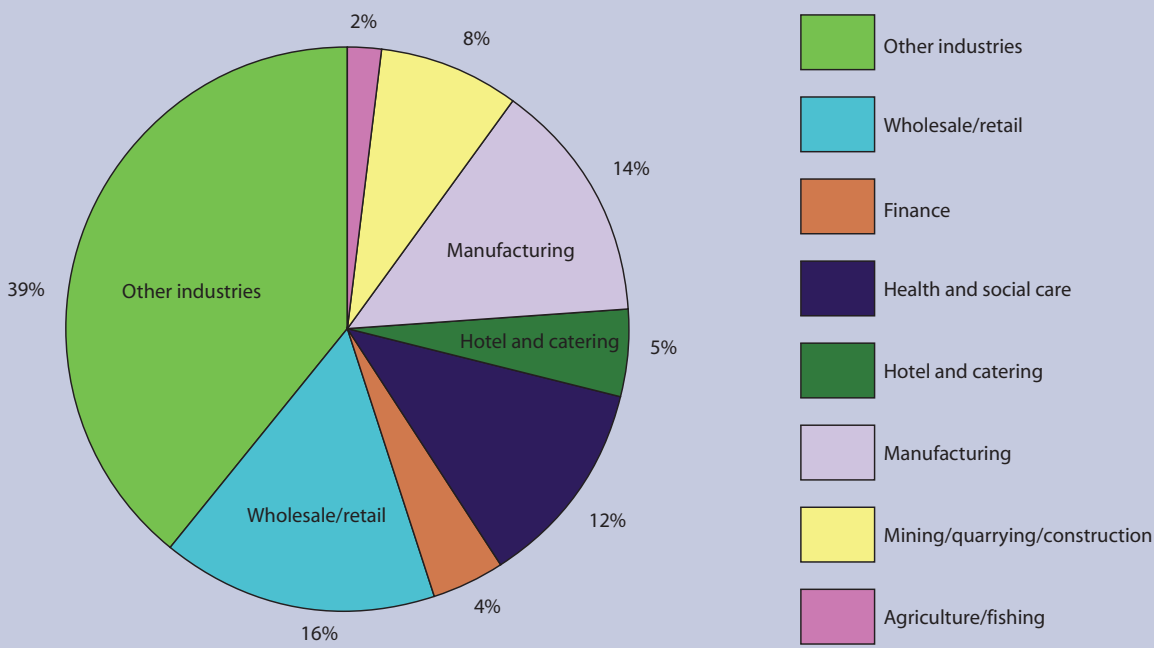

THOR-GP practices
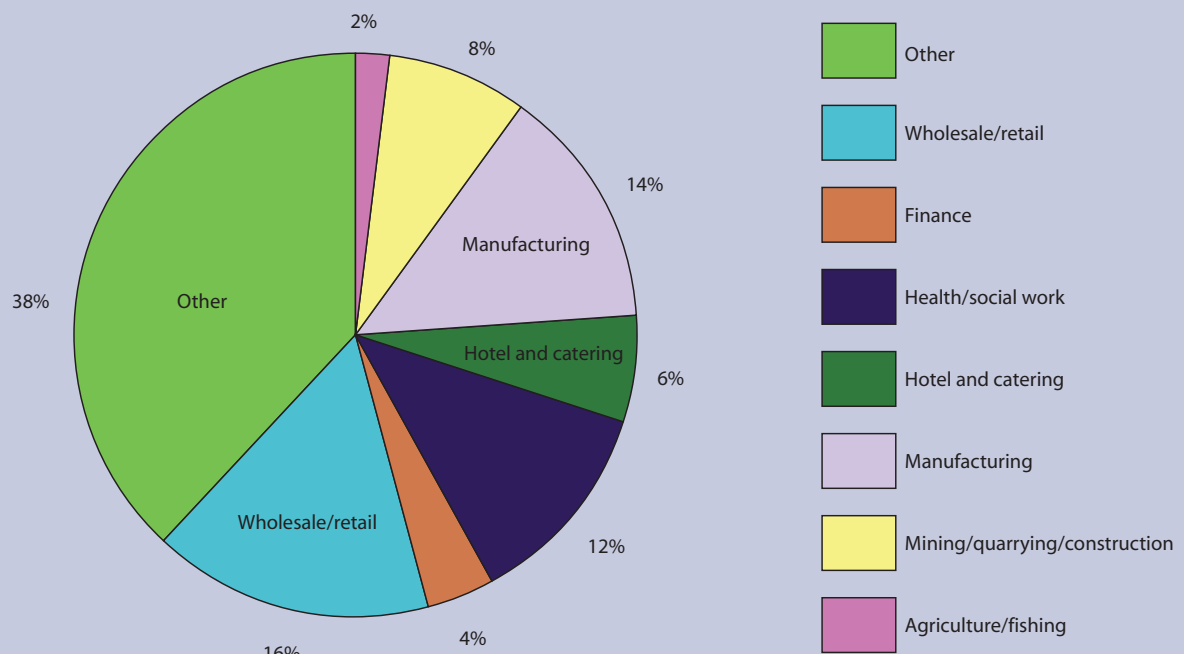

The geographical output areas for the whole of England, Scotland and Wales were pooled together and data provided by the Office for National Statistics gave a proportional breakdown of this population by major industrial group. This was compared to the industrial breakdown of the geographical output areas represented by THOR-GP practices. Interpretation: preliminary data are encouraging and suggest that, using these categories, GPs reporting to THOR-GP are representative of the national distribution. THORP-GP = The Health and Occupation Reporting network in General Practice. 